\title{
Pengaruh Debt to Equity Ratio, Firm Size dan Working Capital terhadap Return on Asset pada Perusahaan Property and Real Estate yang terdaftar di Bursa Efek Indonesia
}

\author{
Diana Felicia \\ Universitas Prima Indonesia \\ Medan, Indonesia \\ dianafelicia9818@gmail.com \\ Rani \\ Universitas Prima Indonesia \\ Medan, Indonesia \\ ranibatubara0311@gmail.com
}

\author{
Sherlyn Margareth \\ Universitas Prima Indonesia \\ Medan, Indonesia \\ $\underline{\text { sherlynmargareth@gmail.com }}$ \\ Enda Noviyanti Simorangkir \\ Lecturer UNPRI \\ Medan, Indonesia \\ endanoviyantisimorangkir@ unprimdn.ac.id
}

Corresponding Author : Enda Noviyanti Simorangkir

Submitted: 12 Juni 2020

Accepted: 21 Agustus 2020

Published: 21 Agustus 2020

\section{ABSTRACT}

This study aims to determine if the independent variables affects dependent variable on Property and Real Estate companies on the Indonesia Stock Exchange from January to December in the period of 2015-2017. Where the independent variables are Debt to Equity Ratio, Firm Size and Working Capital. Whereas, the dependent variable is Return on Asset. Where there are as many as 46 Property and Real Estate companies listed on the Indonesia Stock Exchange. However, the samples are examined only 35 companies in accordance with the desired criteria. This research method uses multiple linear regression analyses with the aid of SPSS 19. The results of this analysis shows in the period of 2015-2017 there is a Property and Real Estate company that on the T test Debt to Equity Ratio is partially no effect on Return On Asset, Firm Size in partial no significant effect on Return on Asset and Working Capital also partial no significant effect on Return on Asset. However, on the F test Debt to Equity Ratio, Firm Size and Working Capital simultaneously have significant effect on Return on Asset. Adjusted $R$ Square at 0,110 or 11\% which means that $11 \%$ variable Return on Asset were influenced by Debt to Equity Ratio, Firm Size and Working Capital while (100\%-11\%) $89 \%$ of its unexplained variable.

Keywords: Debt to Equity Ratio (DER), Firm Size, Working Capital and Return on Asset (ROA) 


\section{PENDAHULUAN}

Dalam menjalankan suatu perusahaan yang bergerak di sektor property and real estate, salah satu hal terpenting adalah dengan memiliki investor. Semakin banyak investor yang berinvestasi pada perusahaan tersebut maka semakin besar juga nilai jual perusahaan tersebut di mata masyarakat. Jika suatu perusahaan memiliki banyak investor, maka laju perkembangan perusahaan tersebut akan semakin baik dan semakin cepat. Dari sini peneliti menyimpulkan bahwa investor berpengaruh besar pada perkembangan suatu perusahaan.

Dari sini peneliti melihat bahwa mengapa seorang investor perlu melihat Debt to Equity Ratio, Firm Size, Working Capital dan Return on Asset dari suatu perusahaan sebelum memberikan keputusan untuk menginvestasikan modal pada perusahaan tersebut atau tidak.

Perusahaan property and real estate di Indonesia yang tercatat di Bursa Efek Indonesia (BEI) sudah tercatat sebanyak 48 perusahaan. Dari sini aja sudah bisa disimpulkan bahwa perusahaan yang bergerak di bidang ini semakin banyak dan semakin berkembang. Karena meningkatnya perusahaan yang bergerak di sektor ini, maka perekonomian di Indonesia pun semakin meningkat dari tahun ke tahun. Karena itu maka peneliti tertarik untuk meneliti perusahaan yang bergerak di bidang property and real estate ini.

Tabel 1.1. Sample Data Debt to Equity Ratio, Firm Size, Working Capital dan Return on Asset pada Perusahaan Property and Real Estate yang terdaftar di Bursa Efek Indonesia pada periode 2015-2017 (Disajikan dalam rupiah)

\begin{tabular}{|c|c|c|c|c|c|c|}
\hline \multirow[b]{2}{*}{$\begin{array}{l}\mathbf{N} \\
\mathbf{o}\end{array}$} & \multirow{2}{*}{$\begin{array}{c}\text { Nama } \\
\text { Emite } \\
\text { n }\end{array}$} & \multirow[b]{2}{*}{ Thn } & DER & FS & WC & ROA \\
\hline & & & Total Ekuitas & Total Aset & Aktiva Lancar & $\begin{array}{c}\text { Laba Bersih } \\
\text { Setelah Pajak }\end{array}$ \\
\hline \multirow{3}{*}{1} & \multirow{3}{*}{ ASRI } & $\begin{array}{c}201 \\
5\end{array}$ & 6.602 .409 .662 & 18.709 .870 .126 & 2.698.917.559 & 684.287 .753 \\
\hline & & $\begin{array}{c}201 \\
6\end{array}$ & 7.187.845.081 & 20.186 .130 .682 & 3.082 .309 .251 & 510.243 .279 \\
\hline & & $\begin{array}{c}201 \\
7\end{array}$ & 8.572 .691 .580 & 20.728 .430 .487 & 2.317 .958 .282 & 1.385 .189 .177 \\
\hline \multirow{5}{*}{2} & \multirow{5}{*}{$\begin{array}{l}\text { MDL } \\
\mathrm{N}\end{array}$} & $\begin{array}{c}201 \\
5\end{array}$ & $\begin{array}{r}6.057 .456 .838 .67 \\
4\end{array}$ & $\begin{array}{r}12.843 .050 .665 .2 \\
29\end{array}$ & $\begin{array}{r}6.805 .277 .762 .30 \\
8\end{array}$ & $\begin{array}{r}873.420 .195 .95 \\
8\end{array}$ \\
\hline & & 201 & 6.595 .334 .000 .46 & 14.540 .108 .285 .1 & 3.921 .828 .260 .10 & 501.349 .673 .18 \\
\hline & & 6 & 0 & 79 & 1 & 8 \\
\hline & & 201 & 7.077.457.731.24 & 14.599 .669 .337 .3 & 3.158 .284 .474 .51 & 614.773 .608 .04 \\
\hline & & 7 & 2 & 51 & 6 & 6 \\
\hline \multirow{3}{*}{3} & \multirow{3}{*}{$\begin{array}{l}\text { SMD } \\
\text { M }\end{array}$} & $\begin{array}{c}201 \\
5\end{array}$ & 2.452 .132 .459 & 3.154 .581 .181 & 1.009 .206 .130 & 75.239 .795 \\
\hline & & $\begin{array}{c}201 \\
6\end{array}$ & $\begin{array}{r}2.475 .866 .647 .01 \\
1\end{array}$ & $\begin{array}{r}3.098 .989 .165 .92 \\
1\end{array}$ & 822.203 .813 .845 & 20.429 .870 .704 \\
\hline & & $\begin{array}{c}201 \\
7\end{array}$ & $\begin{array}{r}2.497 .872 .652 .54 \\
2\end{array}$ & $\begin{array}{r}3.141 .680 .323 .40 \\
3\end{array}$ & 876.583 .776 .938 & 19.737.381.645 \\
\hline
\end{tabular}

Berdasarkan Tabel di atas kita dapat melihat bahwa PT ASRI untuk aktiva lancar dari tahun 2016 ke 2017 mengalami penurunan sebesar $24,79 \%$, sedangkan 
untuk laba bersih setelah pajaknya dari tahun 2016 ke 2017 mengalami kenaikan sebesar $171,47 \%$.

Berdasarkan Tabel diatas kita dapat melihat bahwa PT MDLN untuk total ekuitas dari tahun 2015 ke tahun 2016 mengalami kenaikan sebesar 81,57\%, sedangkan untuk laba bersih setelah pajaknya mengalami penurunan sebesar $42,59 \%$.

Berdasarkan Tabel diatas kita dapat menyimpulkan bahwa PT SMDM untuk total asetnya dari tahun 2016 ke tahun 2017 mengalami peningkatan sebesar 1,37\%, sedangkan untuk laba bersih setelah pajaknya mengalami penurunan sebesar $3,09 \%$.

\section{LANDASAN TEORI}

\subsection{Teori Debt to Equity Ratio (DER)}

Debt to Equity Ratio atau Rasio Hutang terhadap Modal merupakan suatu rasio keuangan yang menunjukkan proporsi relatif antara ekuitas dengan hutang yang digunakan untuk membiayai aset perusahaan.

\subsection{Teori Firm Size}

Firm size atau ukuran perusahaan secara umum bisa diartikan dengan suatu perbandingan besar atau kecilnya suatu perusahaan.

\subsection{Teori Working Capital}

Working capital atau modal kerja merupakan suatu investasi jangka pendek bersih yang dibutuhkan dalam melaksanakan setiap aktivitas sehari-hari yang ada di dalam suatu perusahaan.

\subsection{Teori Return on Asset (ROA)}

Return on Asset adalah suatu rasio keuangan yang menunjukkan atau mengukur kemampuan sebuah perusahaan dengan menggunakan seluruh aktiva yang dimiliki untuk menghasilkan suatu laba setelah pajak. Semakin besar ROA, berarti semakin efisien penggunaan aktiva perusahaan atau suatu jumlah aktiva yang sama bisa dihasilkan laba yang lebih besar.

\section{METODE PENELITIAN \\ Populasi dan Sampel}

Populasi yang ada di Bursa Efek Indonesia dalam sektor Property dan Real Estate sebanyak 46 perusahaan. Diantara 46 perusahaan tersebut yang diambil hanya sebanyak 35 perusahaan yang bergerak di sektor Property and Real Estate sebagai sampel dari jurnal ini, dengan beberapa kriteria yang sudah di tentukan.

\section{HASIL DAN PEMBAHASAN}

A. Hasil Uji Asumsi Klasik

1. Uji Normalitas

Uji ini bertujuan untuk mengetahui suatu data terdistribusi dengan normal atau tidak. a. Uji One-Sample Kolmogorov-Smirnov

Uji Kolmogorof-Smirnov biasanya diuji dengan taraf signifikasi 0,05. Jadi, agar suatu data dapat dinyatakan terdistribusi dengan normal signifikasinya harus lebih besar dari 0,05 .

Tabel 4. 1 Uji Normalitas - KolmogorovSmirnov 


\begin{tabular}{|c|c|c|}
\hline \multicolumn{3}{|c|}{ One-Sample Kolmogorov-Smirnov Test } \\
\hline & & $\begin{array}{l}\text { Unstandardized } \\
\text { Residual }\end{array}$ \\
\hline \multicolumn{2}{|l|}{$\mathrm{N}$} & 77 \\
\hline \multirow{2}{*}{$\begin{array}{l}\text { Normal } \\
\text { Parameters }{ }^{\mathrm{a}, \mathrm{b}}\end{array}$} & Mean & .0000000 \\
\hline & $\begin{array}{l}\text { Std. } \\
\text { Deviation }\end{array}$ & .95337767 \\
\hline \multirow{3}{*}{$\begin{array}{l}\text { Most Extreme } \\
\text { Differences }\end{array}$} & Absolute & .056 \\
\hline & Positive & .056 \\
\hline & Negative & -.046 \\
\hline \multicolumn{2}{|c|}{ Kolmogorov-Smirnov Z } & .493 \\
\hline \multicolumn{2}{|c|}{ Asymp. Sig. (2-tailed) } & .968 \\
\hline \multicolumn{3}{|c|}{$\begin{array}{l}\text { a. Test distribution is Normal. } \\
\text { b. Calculated from data. } \\
\text { Sumber : Hasil Ouput SPSS } 19\end{array}$} \\
\hline
\end{tabular}

c. Metode Grafik Normal Probability Plot

Berdasarkan table di atas bagian data terakhir (Asymp. Sig. (2-tailed) yaitu Uji One-Sample Kolmogorov-Smirnov nilai Asymp.Sig.(2-tailed) yaitu sebesar 0,968 yang artinya lebih besar dari 0,05. Maka, dapat disimpulkan bahwa Uji One-Sample Kolmogorov-Smirnov berdistribusi normal terhadap variable yang ada.

b. Metode Grafik Histogram

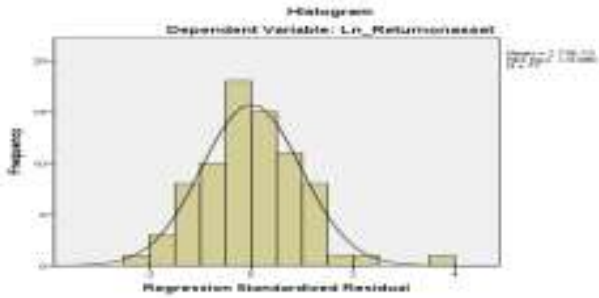

Gambar 4.1 Uji Normalitas - Grafik

Histogram

Sumber : Hasil Ouput SPSS 19

Dari grafik histogram di atas dapat disiimpulkan bahwa grafik tersebut berdistribusi normal karena membentuk kurva simetris.

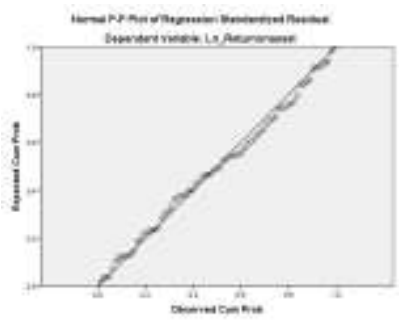

Gambar 4. 2 Uji Normalitas - Grafik Normal Probability Plot

Pada grafik Normal Probability Plot juga dapat dilihat bahwa grafik tersebut berdistribusi normal, karena lingkaranlingkaran kecil tersebut mengikuti garis diagonal dengan membentuk diagonal juga.

\section{Uji Multikolinearitas}

Uji ini digunakan untuk mengetahui apakah ada hubungan yang sempurna maupun hampir sempurna diantara variable bebas hingga sulit untuk memisahkan pengaruh diantara variable tersebut. Uji ini dapat dilihat dari nilai tolerance dan nilai variance Inflation Faktor yang jika nilai tolerance lebih kecil dari 0,1 atau nilai VIF lebih dari 10 maka dinyatakan memiliki masalah multikolineritas

Tabel 4.2 Tabel Uji Multikolinearitas 


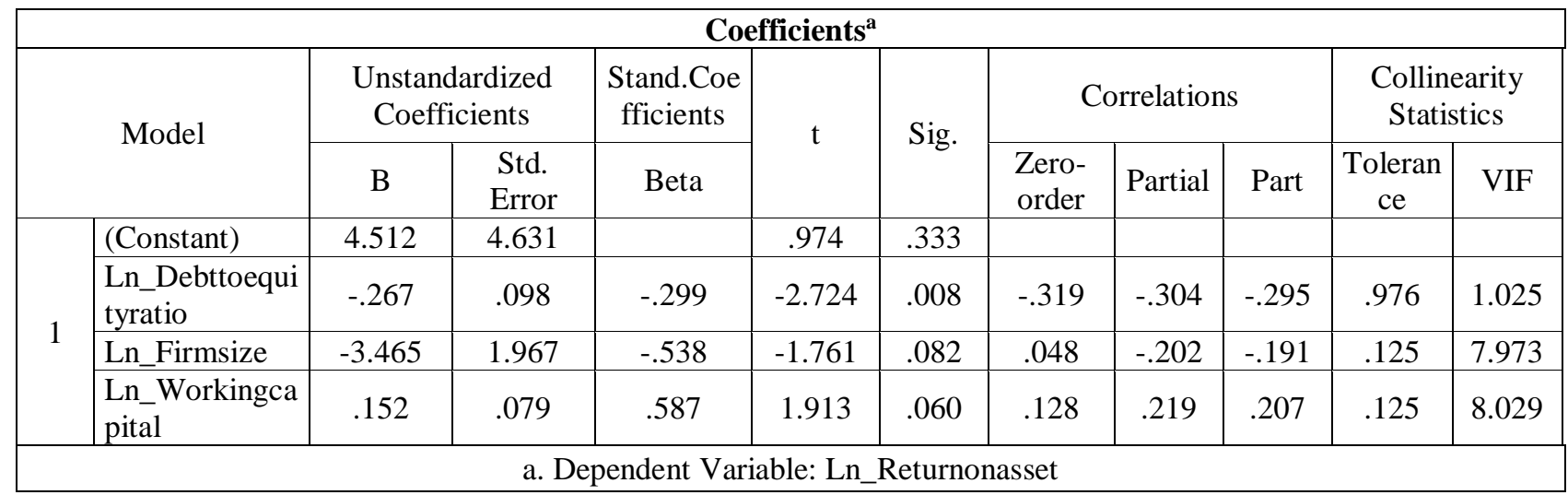

Sumber : Hasil Ouput SPSS 19

Dari table diatas, bagian tolarance untuk Uji Multikolinearitas bahwa nilai Tolerance pada variable Debt to Equity Ratio sebesar 0,976, nilai Tolerance pada variable Firm Size sebesar 0,125 dan nilai Tolerance pada variable Working Capital sebesar 0,125. Dari table tersebut dapat kita lihat bahwa ketiga variable tersebut nilai tolerancenya lebih dari 0,1. Dengan demikian, maka dapat disimpulkan bahwa ketiga variable tersebut dinilai tolerancenya telah terjadi multikolinearitas dalam model regresi.

Untuk Uji Multikolinearitas pada nilai VIF di variable Debt to Equity Ratio sebesar 1,025 , nilai VIF pada variable Firm Size sebesar 7,973 dan nilai VIF pada Working Capital sebesar 8,029. Dari data diatas dapat dilihat bahwa ketiga variable tersebut memiliki nilai VIF yang lebih kecil dari 10 . Maka, dapat disimpulkan bahwa ketiga variable tersebut tidak terjadi multikolinearitas.

\section{Uji Heteroskesdatisitas}

Uji ini bertujuan untuk mengetahui apakah ada ketidaksamaan varian dari residual antara satu pengamat dengan pengamat yang lain. Regresi yang memenuhi syarat adalah jika terdapat kesamaan varian dari residual suatu antara satu pengamat dengan pengamat yang lain tetap.

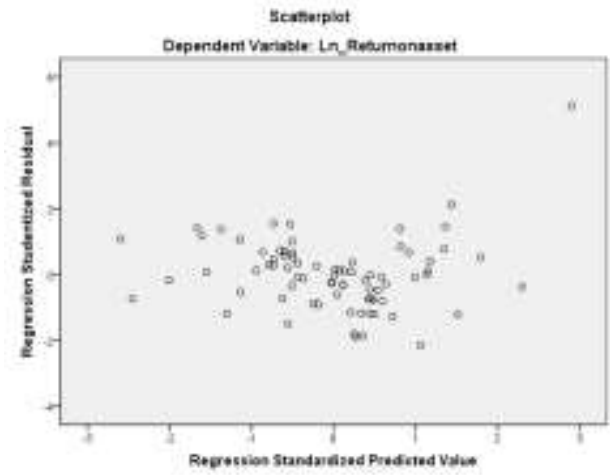

Gambar 4. 3. Uji HeteroskesdatisitasGrafik Scatterplot

\section{Sumber : Hasil Ouput SPSS 19}

Berdasarkan grafik Scatterplot pada table diatas dapat dilihat bahwa lingkaranlingkaran kecil yang ada pada table menyebar dan tidak berkumpul disatu titik yang dapat membentuk suatu pola tertentu, maka dari grafik di atas dapat disimpulkan bahwa grafik tersebut tidak terjadi masalah pada Uji Heteroskesdatisitas.

\section{Uji Autokolereasi}

Menurut Santoso (2014:194), uji ini menggunakan pendekatan D-W (Durbin Watson), yaitu jika nilai D-W dibawah -2 berarti diindikasikan positif, jika nilai D- 
W diantara -2 sampai 2 berarti jika nilai D-W diatas 2 diindikasikan diindikasikan tidak ada autokorelasi dan negative

Tabel 4. 3 Uji Autokorelasi - Tabel Durbin Watson

\begin{tabular}{|c|c|c|c|c|c|c|c|c|c|c|}
\hline \multicolumn{1}{|c|}{$\begin{array}{c}\text { Mode } \\
1\end{array}$} & $\mathrm{R}$ & R Square & $\begin{array}{c}\text { Adjusted R } \\
\text { Square }\end{array}$ & $\begin{array}{c}\text { Std. Error of } \\
\text { the Estimate }\end{array}$ & $\begin{array}{c}\text { R Square } \\
\text { Change }\end{array}$ & $\begin{array}{c}\text { F } \\
\text { Change }\end{array}$ & df1 & df2 & $\begin{array}{c}\text { Sig. F } \\
\text { Change }\end{array}$ & $\begin{array}{c}\text { Durbin- } \\
\text { Watson }\end{array}$ \\
\hline 1 & $.380^{\text {a }}$ & .145 & .110 & .97277 & .145 & 4.118 & 3 & 73 & .009 & 1.864 \\
\hline
\end{tabular}

\section{Sumber : Hasil Ouput SPSS 19}

Dari tabel di atas, di kolom terakhir bagian Durbin Watson dapat kita lihat bahwa nilai Durbin-Watson yaitu sebesar 1,864. Dari hasil tersebut dapat dilihat bahwa nilai DW diantara -2 sampai 2 yang berarti tidak terjadinya autokorelasi.

\section{B. Hasil Analisis Data Penelitian 1. Model Penelitian}

Pengujian hipotesis pada penelitian ini menggunakan model regresi linear berganda, karena variabel bebas yang ada pada penelitian ini lebih dari satu variabel

Tabel 4. 4. Tabel Persamaan Regresi

\begin{tabular}{|c|c|c|c|c|c|c|c|c|c|c|c|}
\hline \multicolumn{12}{|c|}{ Coefficients $^{\mathrm{a}}$} \\
\hline \multirow{2}{*}{\multicolumn{2}{|c|}{ Model }} & \multicolumn{2}{|c|}{$\begin{array}{c}\text { Unstandardized } \\
\text { Coefficients }\end{array}$} & \multirow{2}{*}{$\begin{array}{c}\begin{array}{c}\text { Standardized } \\
\text { Coefficients }\end{array} \\
\text { Beta }\end{array}$} & \multirow{2}{*}{$\mathrm{t}$} & \multirow{2}{*}{ Sig. } & \multicolumn{3}{|c|}{ Correlations } & \multicolumn{2}{|c|}{$\begin{array}{l}\text { Collinearity } \\
\text { Statistics }\end{array}$} \\
\hline & & B & $\begin{array}{l}\text { Std. } \\
\text { Error }\end{array}$ & & & & $\begin{array}{l}\text { Zero- } \\
\text { order }\end{array}$ & Partial & Part & Tolerance & VIF \\
\hline \multirow{4}{*}{1} & (Constant) & 4.512 & 4.631 & & .974 & .333 & & & & & \\
\hline & Ln_Debttoequityratio & -.267 & .098 & -.299 & -2.724 & .008 & -.319 & -.304 & -.295 & .976 & 1.025 \\
\hline & Ln_Firmsize & -3.465 & 1.967 & -.538 & -1.761 & .082 & .048 & -.202 & -.191 & .125 & 7.973 \\
\hline & Ln_Workingcapital & .152 & .079 & .587 & 1.913 & .060 & .128 & .219 & .207 & .125 & 8.029 \\
\hline
\end{tabular}

Sumber : Hasil Ouput SPSS 1 
a. Nilai Constant (a) $=4,512$

Nilai Constant apabila variabel bebas, yaitu Debt to Equity Ratio, Firm Size dan Working Capital bernilai constant maka Return on Asset bernilai 4,512 .

b. Nilai Constant (a) $=4,512$

Nilai Constant apabila variabel bebas, yaitu Debt to Equity Ratio, Firm Size dan Working Capital bernilai constant maka Return on Asset bernilai 4,512.

c. Debt to Equity Ratio $=-0,267$.

Koefisien ini menunjukkan bahwa setiap kenaikan 1 satuan Debt to Equity Ratio, maka Return on Assetnya akan mengalami penurunan sebesar 0,267 dengan syarat variabel yang lain dianggap tetap.

d. Firm Size $=-3,465$.

Koefisien ini menunjukkan bahwa setiap kenaikan 1 satuan Firm Size, maka Return on Asset akan mengalami penurunan sebesar 3,465 dengan syarat variabel yang lain dianggap tetap.

e. Working Capital $=0,152$.

Koefisien ini menunjukkan bahwa setiap kenaikan 1 satuan Working Capital, maka Return on Asset akan mengalami kenaikan juga sebesar 0,152 dengan syarat varibel yang lain dianggap tetap.

\section{Koefisien Determinasi}

Tabel 4. 5. Uji Koefisien Determinasi

\begin{tabular}{|c|c|c|c|c|c|c|c|c|c|c|}
\hline \multicolumn{11}{|c|}{ Model Summary $^{\mathbf{b}}$} \\
\hline \multirow[b]{2}{*}{$\begin{array}{c}\text { M } \\
\text { od } \\
\text { el }\end{array}$} & \multirow[b]{2}{*}{$\mathrm{R}$} & \multirow[b]{2}{*}{$\begin{array}{c}\mathrm{R} \\
\mathrm{Sq} \\
\text { uar } \\
\mathrm{e}\end{array}$} & \multirow[b]{2}{*}{$\begin{array}{c}\text { Adj } \\
\text { uste } \\
\text { d R } \\
\text { Squ } \\
\text { are }\end{array}$} & \multirow[b]{2}{*}{$\begin{array}{l}\text { Std. } \\
\text { Erro } \\
\mathrm{r} \text { of } \\
\text { the } \\
\text { Esti } \\
\text { mat } \\
\mathrm{e}\end{array}$} & \multicolumn{5}{|c|}{ Change Statistics } & \multirow[b]{2}{*}{$\begin{array}{l}\text { Dur } \\
\text { bin- } \\
\text { Wat } \\
\text { son }\end{array}$} \\
\hline & & & & & $\begin{array}{c}\mathrm{R} \\
\text { Squ } \\
\text { are } \\
\mathrm{Ch} \\
\text { ang } \\
\mathrm{e}\end{array}$ & $\begin{array}{c}\mathrm{F} \\
\mathrm{Ch} \\
\text { ang } \\
\mathrm{e}\end{array}$ & $\begin{array}{l}\mathrm{d} \\
\mathrm{f} \\
1\end{array}$ & & $\begin{array}{c}\text { Sig. } \\
\text { F } \\
\text { Ch } \\
\text { ang } \\
\text { e }\end{array}$ & \\
\hline 1 & $\begin{array}{c}.3 \\
8 \\
0^{\mathrm{a}}\end{array}$ & $\begin{array}{c}.14 \\
5\end{array}$ & .110 & $\begin{array}{c}972 \\
77\end{array}$ & $\begin{array}{c}.14 \\
5\end{array}$ & $\begin{array}{c}4.1 \\
18\end{array}$ & 3 & $\begin{array}{l}7 \\
3\end{array}$ & $\begin{array}{c}.00 \\
9\end{array}$ & $\begin{array}{l}1.8 \\
64\end{array}$ \\
\hline & & 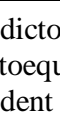 & & Cons & & & & & & \\
\hline
\end{tabular}

Sumber : Hasil Ouput SPSS 19

Dari table di atas, di kolom keempat bagian Adjusted $R$ Square dapat dilihat bahwa nilai Adjusted $R$ sebesar 0,110 atau $11 \%$, yang berarti $11 \%$ variasi pada variable Return on Asset dapat dijelaskan dari Debt to Equity Ratio, Firm Size dan Working Capital, sedangkan sisanya sebesar (100\%-11\%) $89 \%$ nya lagi didapat dari variable lain,seperti Debt to Asset Ratio dan Current Ratio yang tidak dijelaskan di jurnal ini.

\section{Pengujian secara parsial (Uji T)}

Uji $\mathrm{T}$ atau Uji Anova ini digunakan untuk menguji apakah variable-variable independentyang ada berpengaruh nyata atau tidak terhadap variable dependentnya

Tabel 4. 6. Tabel Uji T

\begin{tabular}{|c|c|c|c|c|c|c|c|c|c|c|c|}
\hline \multicolumn{12}{|c|}{ Coefficients $^{\mathrm{a}}$} \\
\hline & \multirow{2}{*}{ Model } & \multicolumn{2}{|c|}{$\begin{array}{l}\text { Unstandardized } \\
\text { Coefficients }\end{array}$} & \multirow{2}{*}{$\begin{array}{c}\begin{array}{c}\text { Standardize } \\
\mathrm{d}\end{array} \\
\text { Coefficients }\end{array}$} & \multirow{2}{*}{$\mathrm{t}$} & \multirow{2}{*}{ Sig. } & \multicolumn{3}{|c|}{ Correlations } & \multicolumn{2}{|c|}{$\begin{array}{l}\text { Collinearity } \\
\text { Statistics }\end{array}$} \\
\hline & & B & Std. Error & & & & $\begin{array}{l}\text { Zero- } \\
\text { order }\end{array}$ & Partial & Part & $\begin{array}{c}\text { Toleranc } \\
\mathrm{e}\end{array}$ & VIF \\
\hline \multirow{4}{*}{1} & (Constant) & 4.512 & 4.631 & & .974 & .333 & & & & & \\
\hline & $\begin{array}{l}\text { Ln_Debttoequityr } \\
\text { atio }\end{array}$ & -.267 & .098 & -.299 & -2.724 & .008 & -.319 & -.304 & -.295 & .976 & 1.025 \\
\hline & Ln_Firmsize & -3.465 & 1.967 & -.538 & -1.761 & .082 & .048 & -.202 & -.191 & .125 & 7.973 \\
\hline & $\begin{array}{l}\text { Ln_Workingcapit } \\
\text { al }\end{array}$ & .152 & .079 & .587 & 1.913 & .060 & .128 & .219 & .207 & .125 & 8.029 \\
\hline
\end{tabular}

a. Dependent Variable: Ln_Returnonasset

\section{Sumber : Hasil Ouput SPSS 19}

Nilai $\mathrm{T}$ untuk probabilitas 0,05 di derajat bebas $\mathrm{n}-\mathrm{k}-1=77-3-1=73$ adalah sebesar 1,993 .
Dari data diatas dapat dilihat bahwa Uji T pada

Debt to Equity Ratio memiliki nilai -2,724< 
1,993 yang berarti nilai thitung lebih kecil dari nilai $t$ table. Maka dapat disimpulkan bahwa H0 diterima, sedangkan Ha ditolak. Jadi, dalam variable Debt to Equity Ratio Uji T tidak berpengaruh signifikan terhadap Return on Asset. Pada Firm Size dapat dilihat bahwa nilai Uji T pada table diatas adalah $-1,761<1,993$ yang berarti nilai t hitung lebih kecil dari nilai t table. Maka, dapat disimpulkan jika H0 diterima, sedangkan Ha ditolak. Jadi, pada variable Firm Size Uji T tidak berpengaruh signifikan juga terhadap Return on Asset. Untuk variable Working Capital dapat dilihat bahwa nilai t hitung juga lebih kecil daripada nilai $t$ table yaitu $1,913<1,993$. Maka, dapat disimpulkan juga bahwa H0 diterima dan Ha ditolak, sehingga pada variable Working Capital tidak berpengaruh signifikan juga terhadap Return on Asset.

\section{Pengujian secara simultan (Uji F)}

Uji F ini kita gunakan untuk mengecheck variable-variable independent yang simultan berpengaruh signifikan terhadap variable dependentnya. Derajat signifikan yang dipakai adalah 0,05. Jika nilai hasil perhitungan Uji $\mathrm{F}$ lebih besar daripada nilai $\mathrm{F}$ menurut tabel maka hipotesisnya bisadisimpulkan bahwa variable independent secara simultan berpengaruh signifikan terhadap variable dependentnya

\begin{tabular}{|c|c|c|c|c|c|c|}
\hline \multicolumn{7}{|c|}{ Tabel 4. 7 Tabel Uji F } \\
\hline \multicolumn{7}{|c|}{ ANOVA $^{b}$} \\
\hline \multicolumn{2}{|c|}{ Model } & $\begin{array}{l}\text { Sum of } \\
\text { Squares }\end{array}$ & $\mathrm{df}$ & $\begin{array}{l}\text { Mean } \\
\text { Square }\end{array}$ & $\mathrm{F}$ & Sig. \\
\hline \multirow[t]{3}{*}{1} & Regression & 11.690 & 3 & 3.897 & 4.118 & $.009^{\mathrm{a}}$ \\
\hline & Residual & 69.079 & 73 & .946 & & \\
\hline & Total & 80.769 & 76 & & & \\
\hline & $\begin{array}{l}\text { edictors: ( } \\
\text { Debttoequi } \\
\text { ependent }\end{array}$ & $\begin{array}{l}\text { ant), Ln_l } \\
\text { o, Ln_Firr } \\
\text { le: Ln_Re }\end{array}$ & & capital, & & \\
\hline
\end{tabular}

Sumber : Hasil Ouput SPSS 19

Pada Uji F nilai signifikan sebesar 5\%. Dari table diatas dapat dilihat bahwa nilai $\mathrm{k}$ sebesar 3 dan derajat pembulat adalah (77-3-1) $=73$. Maka, nilai table $F$ yang diperoleh dari nilai tersebut adalah 2,73. Jadi, nilai yang didapat adalah $4,118>2,73$. Maka, dari hasil tersebut dapat disimpulkan bahwa pada Uji F H0 ditolak, sedangkan H1 diterima. Yang berarti bahwa variable Debt to Equity Ratio, Firm Size dan Working Capital secara simultan berpengaruh terhadap Return on Asset.

\section{Pembahasan Hasil Penelitian 1. Pengaruh Debt to Equity Ratio terhadap Return on Asset}

Berdasarkan hasil penelitian pengujian hipotesis secara parsial bahwa Uji T pada Debt to Equity Ratio memiliki nilai $-2,724<1,993$ yang berarti nilai $t$ hitung lebih kecil dari nilai $t$ table. Maka dapat disimpulkan bahwa H0 diterima, sedangkan Ha ditolak. Jadi, dalam variable Debt to Equity Ratio Uji $\mathrm{T}$ tidak berpengaruh signifikan terhadap Return

on Asset. Penelitian ini sesuai dengan peneliti terdahulu, Trisha (2019), Debt to Equity Ratio tidak berpengaruh terhadap Return on Asset pada penelitiannya Pengaruh TATO, DER dan Current Ratio terhadap ROA pada Perusahaan Property and Real Estate.

\section{Pengaruh Firm Size terhadap Return on Asset}

Pada hasil pengujian secara parsial ditemukan bahwa nilai Firm Size pada Uji T adalah -1,761 $<1,993$ yang berarti nilai t hitung lebih kecil dari nilai $\mathrm{t}$ table. Maka, dapat disimpulkan jika H0 diterima, sedangkan Ha ditolak. Jadi, pada variable Firm Size Uji T tidak berpengaruh signifikan juga terhadap Return on Asset. Penelitian ini sesuai dengan peneliti sebelumnya, Nopita Sari (2019), yang menyimpulkan bahwa Firm Size tidak berpengaruh signifikan terhadap Return on Asset terhadap penelitiannya terhadap Pengaruh Current Ratio, Debt to Equity Ratio, Firm Size dan Perputaran Modal Kerja terhadap Profitabilitas (ROA) pada Perusahaan Wholesale dan Retail Trade yang Terdaftar Di Bursa Efek Indonesia pada Periode 2013-2017.

\section{Pengaruh Working Capital terhadap Return on Asset}


Hasil pengujian secara parsial di ketahui jika nilai Working Capital pada Uji $\mathrm{T}$ juga lebih kecil daripada nilai t table yaitu 1,913 < 1,993. Maka, dapat disimpulkan juga bahwa H0 diterima dan Ha ditolak, sehingga pada variable Working Capital tidak berpengaruh signifikan juga terhadap Return on Asset. Penelitian ini menunjukkan sesuai dengan peneliti Yocky (2014), Working Capital tidak berpengaruh secara parsial terhadap Return on Asset terhadap penelitiannya terhadap Pengaruh Perputaran Kas dan Modal Kerja terhadap Profitabilitas pada Perusahaan Makanan dan Minuman yang terdaftar di Bursa Efek Indonesia periode 2009-2013.

\section{Pengaruh Debt to Equity Ratio, Firm Size dan Working Capital terhadap Return on Asset}

Pada pengujian Uji $\mathrm{F}$ secara simultan, nilai yang didapat adalah 4,118> 2,73. Maka, dari hasil tersebut dapat disimpulkan bahwa pada Uji F H0 ditolak, sedangkan H1 diterima. Yang berarti variable Debt to Equity Ratio, Firm Size dan Working Capital secara simultan berpengaruh terhadap Return on Asset. Penelitian ini sejalan dengan penelitian Jeni Susati dan Made Dana (2015), yang menyimpulkan bahwa Debt to Equity Ratio, Working Capital dan Firm Size berpengaruh secara simultan terhadap Return on Asset terhadap penelitiannya mengenai Pengaruh Working Capital, Firm Size, Debt to Equity Ratio dan Financial Fixed Asset ratio terhadap Profitabilitas.

\section{KESIMPULAN DAN SARAN}

\section{A. Kesimpulan,}

1) Debt to Equity Ratio secara parsial tidak berpengaruh signifikan terhadap Return on Asset pada Perusahaan Property and Real Estate di BEI pada tahun 2015-2017. 2) Firm Size secara parsial tidak berpengaruh signifikan terhadap Return on Asset pada Perusahaan Property and Real Estate di BEI pada tahun 2015-2017. 3) Working Capital secara parsial tidak berpengaruh signifikan terhadap Return on Asset pada Perusahaan Property and Real Estate di BEI pada tahun 2015-2017. 4) Debt to Equity Ratio, Firm Size dan Working Capital secara simultan berpengaruh signifikan terhadap Return on Asset pada Perusahaan Property and Real Estate di BEI pada tahun 2015-2017.

B. Saran

1. Bagi Perusahaan Property and Real Estate agar lebih memperhatikan dan meningkatkan Debt to Equity Ratio, Firm Size dan Working Capitalnya terhadap perusahaan agar Return on Asset yang ada diperusahaan dapat meningkat. 2. Bagi Peneliti selanjutnya, peneliti berharap kalian dapat meneliti variabel-variabel lain yang dapat berpengaruh terhadap Return on Asset pada perusahaan Property and Real Estate yang ada di BEI.

Bagi Universitas Prima Indonesia, peneliti berharap jika kampus bersedia untuk menambah beberapa buku diperpustakaan mengenai Property and Real Estate agar para peneliti selanjutnya dapat menambah wawasan yang baru.

\section{DAFTAR PUSTAKA}

Dewi, Ni Kadek Venimas Citra, Wayan Cipta dan I Ketut Kirya. 2015. Pengaruh LDR, LAR, DER dan CR terhadap ROA. Jurusan Manajemen, Volume 3, Tahun 2015.

Ghozali,Imam. 2006. Aplikasi Analisis Multivariete dengan program SPSS. Semarang: Universitas Diponegoro.

Ghozali, H.M. 2012. Aplikasi Analisis Multivariate dengan Program IBM SPSS. Semarang: Badan Pener bit Universitas Diponegoro.

Hartono, Jogiyanto. 2008. Teori Portofolio dan Analisis Investasi. Edisi Kelima. Yogyakarta: BPFE.

Hendrayanti, Heny. Pengaruh Ukuran Perusahaan (Firm Size) dan Likuiditas Saham terhadap Fenomena Price Reversal.

Hurriyati, Ratih dan Muji Gunarto. 2019. Metode Statistika Bisnis untuk Bidang Ilmu Manajemen dengan Aplikasi Program SPSS. Bandung: PT Refika Aditama.

Ismail, Fajri. 2018. Statistika Untuk Penelitian Pendidikan dan Ilmu-ilmu Sosial. Jakarta: Prenadamedia Group. 
Kutner,M.H., C.J. Nachtsheim., dan J. Neter. 2004. Applied Linear Regression models. $4^{\text {th }} \boldsymbol{e d}$. New York: McGrawHill Companies, Inc.

Lesmono, Muhammad Andrei. 2018. Pengaruh Modal Kerja terhadap Profitabilitas pada Industri Dasar dan Kimia di Bursa Efek Indonesia. Jurnal Disrupsi Bisnis, Vol. 1, No. 1, Juli 2018.

Mulyana, Yocky Ardiansyah. 2014. Pengaruh Perputaran Kas dan Modal Kerja terhadap Profitabilitas pada Perusahaan Makanan dan Minuman yang terdaftar di Bursa Efek Indonesia periode 2009-2013. Jurnal Riset Manajemen, 2014.

Riyanto,B. 2013. Dasar-dasar Pembelanjaan Perusahaan, Edisi Keempat. Yogyakarta: BPFE.

Sari, Nopita dkk. 2019. Pengaruh Current Ratio, Debt to Equity Ratio, Firm Size dan Perputaran Modal Kerja terhadap Profitabilitas (ROA) pada Perusahaan Wholesale dan Retail Trade yang Terdaftar Di Bursa Efek Indonesia pada Periode 2013-2017. Riset dan Jurnal Akuntansi, Volume 3 Nomor 2, Agustus 2019.

Siregar, Syofian. 2017. Statistik Parametrik untuk Penelitia $n$ Kuantitatif dilengkapi dengan Perhitungan Manual dan Aplikasi SPSS Versi 17. Jakarta: PT Bumi Aksara.

Suharyadi dan Purwanto. 2004. Statistika: Untuk Ekonomi dan Keuangan Modern. Jakarta: Salemba Empat.

Susanti, Jeni dan Made Dana Saputra. 2015. Pengaruh Working Capital, Firm Size, Debt to Equity Ratio dan Financial Fixed Asset ratio terhadap Profitabilitas. Jurnal Valid, Vol. 12 No.3 , Juli 2015 : 379-387.

Wanny, Trisha, dkk. 2019. Pengaruh TATO, DER dan Current Ratio terhadap ROA pada Perusahaan Property and Real Estate. Riset dan Jurnal Akuntansi, Volume 3 Nomor 2, Agustus 2019. https://doi.org/10.33395/owner.v3i2. $\underline{127}$

http://junaidichaniago.wordpress.com

https://muhammadilhammubarok.wordpress.co $\mathrm{m} / 2018 / 08 / 09 /$ regresi-linearberganda-dasar-teori/

http://trandingbyknowledge.blogspot.com/201 3/07/debt-to-equity-ratioder.html?m=1

http://duwiconsultant.blogspot.com/2011/11/a nalisis-regresi-linierberganda.html? $\mathrm{m}=1$

https://www.statistikan.com/2017/01/ujiautokorelasi-durbin-watsonspss.html

https://www.simulasikredit.com/apa-ituworking-capital-definisi-workingcapital/

https://media.neliti.com/media/publications/25 3368-pengaruh-profitabilitas-ukuranperusahaa-8494d0 